\title{
Influence of Sintering Temperature on Structural and Morphology of $\mathrm{La}_{0.7} \mathrm{Ba}_{0.25} \mathrm{Nd}_{0.05} \mathrm{MnO}_{3}$
}

\author{
$1^{\text {st }}$ D.R. Munazat ${ }^{1}, 2^{\text {nd }}$ D.S. Razaq ${ }^{1}, 3^{\text {rd }}$ Bambang Soegijono $^{1}, 4^{\text {th }}$ Budhy Kurniawan $^{1}, 5^{\text {th }}$ S. \\ Budiawanti ${ }^{2}, 6^{\text {th }}$ Dwi Nanto ${ }^{3}$ \\ \{bkuru@fisika.ui.ac.id ${ }^{1}$,dwi.nanto@uinjkt.ac.id $\left.{ }^{3}\right\}$ \\ Department of Physics, Universitas Indonesia, Depok 16424, Indonesia ${ }^{1}$, Faculty of Teacher Training \\ and Education, Sebelas Maret University, Solo 57126, Indonesia ${ }^{2}$, Department of Physics Education, \\ Syarif Hidayatullah State Islamic University, Jakarta 15412, Indonesia ${ }^{1}$
}

\begin{abstract}
Perovskite manganite of $\mathrm{La}_{0.7} \mathrm{Ba}_{0.25} \mathrm{Nd}_{0.05} \mathrm{MnO}_{3}$ (LBNMO) has been investigated in this report. The LBNMO synthesized by sol-gel method. We examined several temperature treatments for 24 hours to study their effect on structure and microstructure. We use X-ray diffractometer (XRD), X-ray fluorescence (XRF) and Scanning Electron Microscope (SEM) to confirm each instrument result on the influence of the structure and morphology of LBNMO. Interestingly, we found that as sintering temperature increased, the structure did not change. Moreover, there was no significant affect of its lattice parameter. By means of XRF, we found the LBNMO keep on the stoichiometry composition. Then, according to SEM investigation, it showed greater grain as temperature increase. Therefore, sintering on variance temperature at certain time plays an important rule on structure and microstructure of the LBNMO.
\end{abstract}

Keywords: Perovskite manganite; Sintering Temperature; structure and microstructure;

\section{Introduction}

Perovskite manganite formula of RE1-xAExMnO3 which $\mathrm{RE}$ is a rare-earth metal $(\mathrm{RE}=$ $\mathrm{La}, \mathrm{Nd}, \mathrm{Pr})$ and $\mathrm{AE}$ is a divalent alkaline-earth such as $(\mathrm{AE}=\mathrm{Ba}, \mathrm{Sr}, \mathrm{Ca})$ has increased the interest of many researchers to investigate any alternative magnetic materials [1-5]. Due to, partial substitution of RE with divalent alkaline-earth ion from formula makes the valence of $\mathrm{Mn3}+$ and $\mathrm{Mn} 4+$ mixture on the Mn-site, which is important influences the interaction ferromagnetic double exchange (DE) couplings by changing the Mn3+-O- Mn4+ bond angle and $\mathrm{Mn}-\mathrm{O}$ bond length [6]. The double exchange phenomenon attracts a lot of attention because it has strange electrical and magnetic properties, especially the property of colossal magnetoresistance (CMR) and magnetocaloric effect (MCE) [5-7].

There have been many perovskite manganite materials investigated. One of them $\mathrm{La} 0.7 \mathrm{Ba} 0.25 \mathrm{Nd} 0.05 \mathrm{MnO} 3$ (LBNMO) is a potential material for CMR and MCE applications, because it has Curie temperature achieved to near room temperature ( $\mathrm{TC}=293 \mathrm{~K})$, as reported by Unlu et al [7]. They synthesized the LBNMO by sol-gel method. Because at Curie temperature the perovskite manganite materials usually exhibit the CMR and MCE around their ferromagnetic (FM) - paramagnetic (PM) phase transition temperature (TC) [7]. The $\mathrm{La} 0.7 \mathrm{Ba} 0.25 \mathrm{Nd} 0.05 \mathrm{MnO} 3$ has attracted our attention to explore more of this material by 
similar route. We examine the effect of sintering temperature on structural, morphologies and of the LBNMO more. The reason is because the preparation and sintering conditions also determine the nature of the grain surface area, influencing the role in electricity transportation, magnetotransport, and magnetic. The advantages synthesized with sol-gel are two which are good homogenetic and low processing temperatures [6].

\section{Experiments}

The sol-gel method prepares the LBNMO sample. The raw materials are $\mathrm{La}_{2} \mathrm{O}_{3}$ (Aldrich, 99.5\%) and $\mathrm{Nd}_{2} \mathrm{O}_{3}$ (Aldrich, 99.5\%) was dissolved by nitrate acid and aquabidest to get nitrate solution form. Stoichiometric calculations obtained from nitrate precursor reagents $\mathrm{Ba}\left(\mathrm{NO}_{3}\right)_{2}$ (Merck, 99\%) and $\mathrm{Mn}\left(\mathrm{NO}_{3}\right) .4 \mathrm{H}_{2} \mathrm{O}$ (Merck, 98.5\%) were dissolved in aquabidest. All precursors were mixed to the beaker glass and added citric acid $\mathrm{C}_{6} \mathrm{H}_{8} \mathrm{O}_{7} \cdot \mathrm{H}_{2} \mathrm{O}$ (Merck 99.5\%). The solution obtained is to heat the heat plate under a constant stirrer at $80{ }^{\circ} \mathrm{C}$ so that the water disappears and a thick gel is obtained. The gel is dried at $120{ }^{\circ} \mathrm{C}$ for one night and then calcined at $600{ }^{\circ} \mathrm{C}$ for 6 hours. Finally, the powder is sintered with temperature differences at $700{ }^{\circ} \mathrm{C}, 800{ }^{\circ} \mathrm{C}$ and $900{ }^{\circ} \mathrm{C}$ for 24 hours.

The existence of this phase structure is indicated by of X-ray diffraction (XRD) at room temperature with $\mathrm{Cu} K_{\alpha}$ radiation $(\lambda=1.5406 \AA)$. The chemical composition measured by) Xray fluorescence (XRF). Scanning electron microscopy (SEM) was carried out to investigate the size of morphological and particles of powder samples at room temperature.
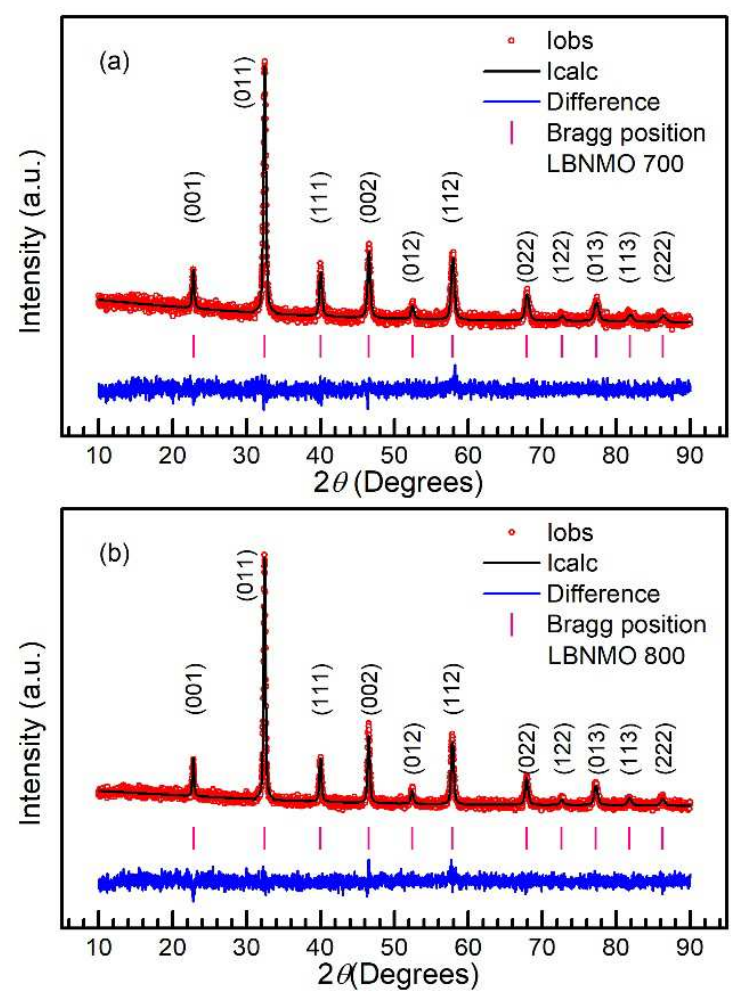




Figure 1. Rietveld analysis of XRD pattern for $\mathrm{La}_{0.7} \mathrm{Ba}_{0.25} \mathrm{Nd}_{0.05} \mathrm{MnO}_{3}$

\section{Result and Discussions}

Each sample has a parameter structure that is enhanced by the rietveld refinement analysis. The rietveld refinement showed a good agreement between the calculated and observed position of diffraction pattern. Rietveld refinement plot analysis of XRD pattern result depicted in Figure 1 reveal materials has single phase. The values studied with those calculated must have good suitability based on the criteria Goodness of Fit (GoF) and Reliability factors $\left(R_{P}\right.$ and $\left.R_{W P}\right)$ shown in Table 1 . The XRD patterns each sample with different sintering temperature has the same pattern is confirmed on the cubic structure owned by the part pm-3m room. It is the same as reported by Ünlü et al. in the parental compound $\mathrm{La}_{0.7} \mathrm{Ba}_{0.25} \mathrm{Nd}_{0.05} \mathrm{MnO}_{3}$ has a cubic structure [7]. There was no significant change of its lattice parameter observed at different sintering temperature summarized in Table 1.

The average crystallite sizes of each sample were calculated from the XRD peak width by using the Scherrer's equation:

$$
D_{S C}=\frac{0.9 \lambda}{\beta_{H K L} \cos \theta}
$$

where $\mathrm{D}_{S C}$ is average crystallite size, $\lambda$ is $\mathrm{Cu}-K \alpha \quad(1.5406 \AA), \beta_{H K L}$ is full-width at half maximum (FWHM) of the Bragg peaks [2]. The average crystallite size of samples sintering at $700{ }^{\circ} \mathrm{C}, 800{ }^{\circ} \mathrm{C}$ and $900{ }^{\circ} \mathrm{C}$ are found to be $17.99,23.19$, and $29.12 \mathrm{~nm}$, respectively (Table 1).

The results calculated for the average crystallite sizes have increased, with increasing sintering temperatures and in the nanocrystalline range. In fact, the size of the crystallite is calculated comparable to that obtained from SEM. From figure 2 shows the change in the highest intensity of reflection (011), an increase in the intensity value and FWHM. Below is the result of an increase in particle size and sintering temperature [3]. 


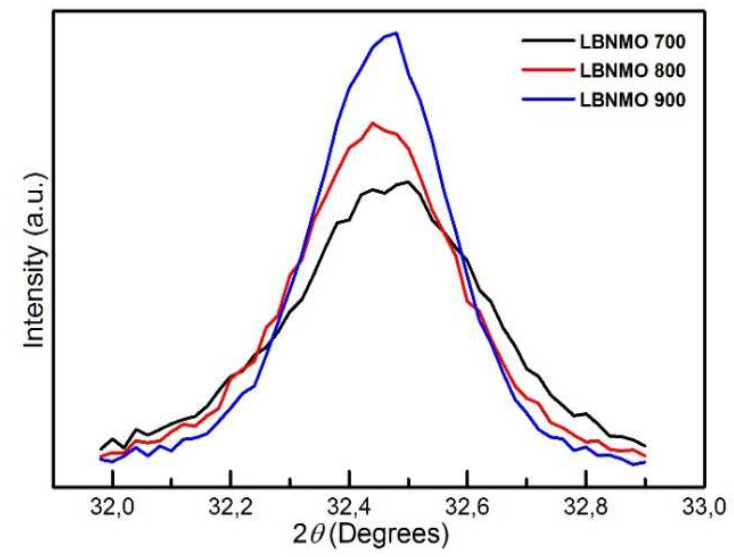

Figure 2. The variation in intensity and $2 \theta$ of the most intense (011) peak with sintering temperature

Figure 3 shows the LBNMO sample morphology sintered at 700,800 and $900^{\circ} \mathrm{C}$ for SEM images. There is a uniform particle size distribution for the sample and if the sintering temperature increases, the particle size will also increase, this is revealed by SEM observations. Refers to many studies reported on the influence of sintering temperatures. The size of the particles or grains becomes larger as the temperature of sintering increases [1-6].

Table 1. Rietveld analysis structural parameter from observed XRD pattern of LBNMO at sintering temperature $700{ }^{\circ} \mathrm{C}, 800^{\circ} \mathrm{C}$ and $900^{\circ} \mathrm{C}$.

\begin{tabular}{cccc}
\hline Paramater & \multicolumn{3}{c}{ Temperature $\left({ }^{\circ} \mathrm{C}\right)$} \\
\cline { 2 - 4 } & \multicolumn{1}{c}{70000} & 900 \\
\hline Crystal structure & Cubic & cubic & cubic \\
& pm- & pm- & pm- \\
Space Group & $3 \mathrm{~m}$ & $3 \mathrm{~m}$ & $3 \mathrm{~m}$ \\
& 3.902 & 3.905 & 3.908 \\
$a=b=c(\AA)$ & 0 & 9 & 6 \\
Volume Unit Cell & 59.40 & 59.58 & 59.71 \\
$\left(\AA^{3}\right)$ & 96 & 85 & 35 \\
& 1.951 & 1.953 & 1.954 \\
$\mathrm{~d}_{<\text {Mn-O }>}(\AA)$ & 0 & 1 & 3 \\
$<$ Mn-O-Mn> & & 180 & 180 \\
$($ degrees $)$ & 180 & 23.19 & 29.12 \\
Average & 17.99 & 19 & 34 \\
Crystallites size $(\mathrm{nm})$ & 81 & & \\
discrepancy & & 1.175 & 1.289 \\
factor & 1.180 & 1 & 4 \\
& 7 & 6.758 & 7.069 \\
GoF & 6.612 & 1 & 9 \\
$\mathrm{R}_{\mathrm{wP}}$ & 9 & &
\end{tabular}






The element composition sample measured by X-Ray Fluorescence (XRF) to confirm what elements are contained in $\mathrm{La}_{0.7} \mathrm{Ba}_{0.25} \mathrm{Nd}_{0.05} \mathrm{MnO}_{3}$. The XRF spectra can be seen in Figure 3 , sintered at different temperature produce the same spectrum without any sign of impurities. The concentration of the contained elements can be seen in table 2. The concentration of measurement results close from the stoichiometry calculation. The differences in measurement results with stoichiometry calculations because XRF is a semi-qualitative analysis.



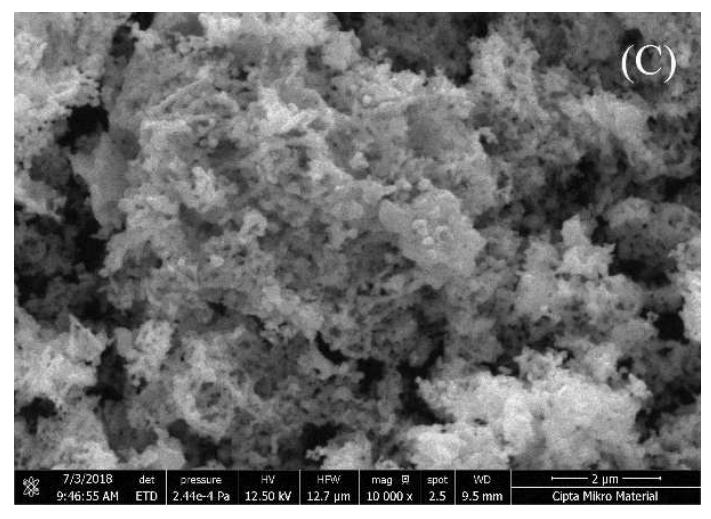

Figure 3. SEM imange from $\mathrm{La}_{0.7} \mathrm{Ba}_{0.25} \mathrm{Nd}_{0.05} \mathrm{MnO}_{3}$
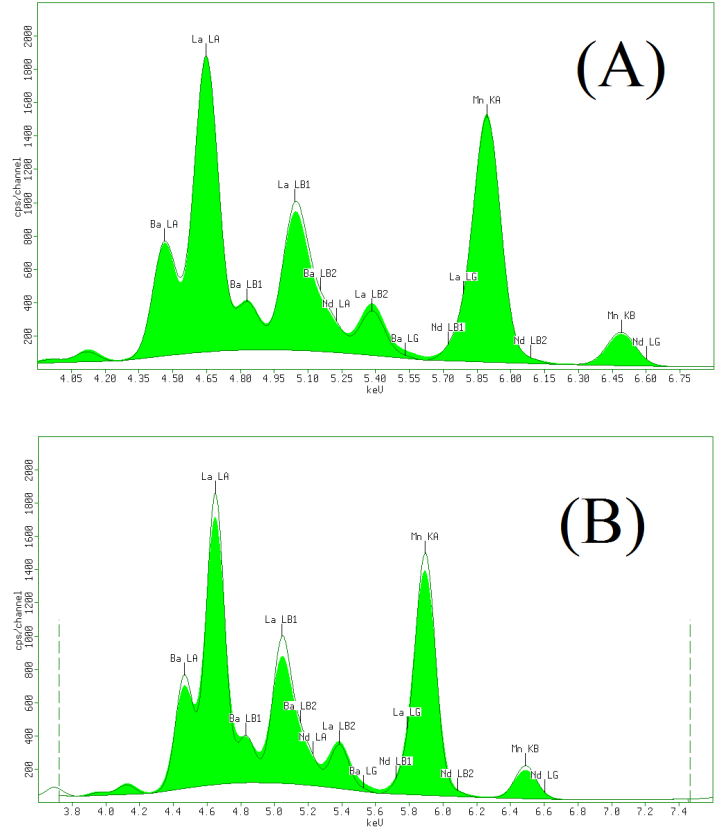




Figure 4. XRF spectra of $\mathrm{La}_{0.7} \mathrm{Ba}_{0.25} \mathrm{Nd}_{0.05} \mathrm{MnO}_{3}$

Table 2. XRF REsult from LBNMO compared to calculation based on stoichiometry.

\begin{tabular}{|c|c|c|c|c|}
\hline $\begin{array}{l}\text { Sintering temperature } \\
\quad\left({ }^{\circ} \mathrm{C}\right)\end{array}$ & $0^{70}$ & 800 & $00^{9}$ & $\begin{array}{l}\text { calc } \\
\text { ulated }\end{array}$ \\
\hline Element & \multicolumn{4}{|c|}{ Concentration (\%) } \\
\hline \multirow{3}{*}{$\mathrm{Mn}$} & 28. & 28. & 2 & 28.3 \\
\hline & 16 & 29 & 8.27 & 6 \\
\hline & 14. & 13. & 1 & 17.7 \\
\hline \multirow[t]{2}{*}{$\mathrm{Ba}$} & 03 & 82 & 4.03 & \\
\hline & 54. & 54. & 5 & 50.1 \\
\hline \multirow[t]{2}{*}{$\mathrm{La}$} & 35 & 71 & 4.43 & 9 \\
\hline & 3.4 & 3.1 & 3. & 377 \\
\hline $\mathrm{Nd}$ & 6 & 8 & 27 & 3.12 \\
\hline \multirow[b]{2}{*}{ Total } & 10 & 100 & 1 & 100. \\
\hline & 0.00 & .00 & 00.00 & 00 \\
\hline
\end{tabular}

\section{Conclusion}

In conclusion, the influence of sintering temperature on structure and morphology was investigated. The $\mathrm{La}_{0.7} \mathrm{Ba}_{0.25} \mathrm{Nd}_{0.05} \mathrm{MnO}_{3}$ material had been successfully synthesized by using sol-gel method. The result of Rietveld refinement analysis showed that all samples are cubic structure with space group $\mathrm{Pm}-3 \mathrm{~m}$. There was no significant change of its lattice parameter observed at different sintering temperature. The average crystallite size for XRD data with Scherrer's equation and particle size increase with increase sintering temperature.

Acknowledgements. This paper in conjuction with the 1st International Conference on Islam, Science and Technology (ICONIST) 2018

\section{References}

[1] A. E.-M. A. Mohamed and B. Hernando, "The expected low field magnetocaloric effect of La $0.7 \mathrm{Ba} 0.3 \mathrm{MnO}_{3}$ manganite at room temperature," Physics Letters A, vol. 380, no. 20, pp. 1763-1766, Apr. 2016.

[2] H. Baaziz, N. K. Maaloul, A. Tozri, H. Rahmouni, S. Mizouri, K. Khirouni, and E. Dhahri, 
"Effect of sintering temperature and grain size on the electrical transport properties of La0.67 $\mathrm{Sr}_{0.33} \mathrm{MnO}_{3}$ manganite," Chemical Physics Letters, vol. 640, pp. 77-81, Nov. 2015.

[3] A. Gaur and G. D. Varma, "Sintering temperature effect on electrical transport and magnetoresistance of nanophasic $\mathrm{La}_{0.7} \mathrm{Sr}_{0.3} \mathrm{MnO}_{3}$," Journal of Physics: Condensed Matter, vol. 18, no. 39, pp. 8837-8846, Sep. 2006.

[4] S. B. Li, C. B. Wang, H. X. Liu, L. Li, Q. Shen, M. Z. Hu, and L. M. Zhang, "Effect of sintering temperature on structural, magnetic and electrical transport properties of $\mathrm{La} 0.67 \mathrm{Ca} 0.33 \mathrm{MnO}_{3}$ ceramics prepared by Plasma Activated Sintering," Materials Research Bulletin, vol. 99, pp. 73-78, Mar. 2018.

[5] M. Oumezzine, O. Peña, T. Guizouarn, R. Lebullenger, and M. Oumezzine, "Impact of the sintering temperature on the structural, magnetic and electrical transport properties of doped $\mathrm{La} 0.67 \mathrm{Ba}_{0.33} \mathrm{Mn}_{0.9} \mathrm{Cr}_{0.1} \mathrm{O}_{3}$ manganite," Journal of Magnetism and Magnetic Materials, vol. 324, no. 18, pp. 2821-2828, Sep. 2012.

[6] G. Venkataiah, Y. Kalyana, and P. Venugopal, "Influence of Sintering Temperature on Magnetotransport Behavior of Some Nanocrystalline Manganites," Sintering - Methods and Products, Mar. 2012.

[7] C. G. Ünlü, Y. E. Tanış, M. B. Kaynar, T. Şimșek, and Ş. Özcan, "Magnetocaloric effect in La0.7 $\mathrm{Nd}_{x} \mathrm{Ba}(0.3-x) \mathrm{MnO}_{3}(x=0,0.05,0.1)$ perovskite manganites," Journal of Alloys and Compounds, vol. 704, pp. 58-63, May 2017. 